\title{
Effect of hysterectomy on colonoscopy completion rate
}

\author{
Mélanie Lacasse MD CCFP ${ }^{1}$, Geneviève Dufresne MD CCFP ${ }^{1}$, Emilie Jolicoeur MD FRCPC ${ }^{1}$, \\ Luc Rochon MD FRCPC ${ }^{1}$, Charles Sabbagh MD FRCPC ${ }^{1}$, Jocelyn Deneault MD FRCPC ${ }^{1}$, Valérie Walsh BA ${ }^{1}$, \\ Isabelle Gaboury PhD², Philip Hassard MD FRCPC
}

M Lacasse, G Dufresne, E Jolicoeur, et al. Effect of hysterectomy on colonoscopy completion rate. Can J Gastroenterol 2010;24(6): 365-368.

BACKGROUND: Several studies show that colonoscopies are technically more difficult to perform in women than men, especially in women who have undergone abdominal and gynecological surgeries. A review of the literature indicates an increased rate of noncompletion of colonoscopies in most cases; however, no studies have investigated the procedural complication rate, sedation requirements and perception of pain in colonoscopies.

OBJECTIVE: To determine whether women who have undergone a previous hysterectomy have a higher noncompletion rate when undergoing a colonoscopy, and to assess whether there is a higher percentage of complications. Furthermore, the present study also aimed to ascertain whether these women required more sedation and whether their perception of pain is greater than that of women who did not undergo previous abdominal surgeries.

METHODS: The present study was a prospective cohort study of women, 45 to 80 years of age, who underwent colonoscopy $(n=508)$. A total of 229 patients were eligible for the study; they completed a questionnaire, and were subsequently divided into control and hysterectomy groups. Gastroenterologists performed all procedures. After colonoscopy, the patient and endoscopist completed a pain perception questionnaire. Cecal intubation rates were also recorded.

RESULTS: No significant difference for cecal intubation rates were detected between the two groups $(95.7 \%$ and $98.7 \%$ in hysterectomy and control groups, respectively; $\mathrm{P}=0.176$ ). The crude $\mathrm{OR}$ for the success rate was 0.29 (95\% CI 0.05 to 1.90 ). There was no significant difference between groups regarding sedation or the type of colonoscope. No correlation between the gastroenterologists' evaluation of pain and patients' pain was observed.

CONCLUSION: Hysterectomy did not significantly diminish the cecal intubation rate, and there was no detectable difference in pain perception or sedative dose. Colonoscopy remains an excellent screening and diagnostic tool for all women.

\section{L'effet de l'hystérectomie sur le taux de complétion d'une colonoscopie}

\begin{abstract}
HISTORIQUE : Plusieurs études démontrent que la colonoscopie est techniquement plus difficile à effectuer chez les femmes que chez les hommes, notamment chez celles qui ont subi une opération abdominale ou gynécologique. Une analyse bibliographique indique un taux plus élevé de non-complétion des colonoscopies dans la plupart des cas, mais aucune étude n'a porté sur le taux de complications de l'intervention, les besoins de sédation et la perception de la douleur en cas de colonoscopie.
\end{abstract}

OBJECTIF : Déterminer si les femmes qui ont déjà subi une hystérectomie ont un taux de non-complétion plus élevé lorsqu'elles subissent une colonoscopie et évaluer si le pourcentage de complications est plus élevé. De plus, la présente étude visait à établir si ces femmes avaient besoin d'une plus grande sédation et si leur perception de la douleur était plus élevée que celle des femmes qui n'ont jamais subi de chirurgie abdominale.

MÉTHODOLOGIE : La présente étude était une étude prospective de cohorte chez des femmes de 45 à 80 ans qui ont subi une colonoscopie $(\mathrm{n}=508)$. Au total, 229 patientes étaient admissibles à l'étude. Elles ont rempli un questionnaire, puis ont été réparties entre un groupe témoin et un groupe d'hystérectomie. Des gastroentérologues ont exécuté toutes les interventions. Après la colonoscopie, les patientes et l'endoscopiste ont rempli un questionnaire de perception de la douleur. On a également consigné les taux d'intubation cæcale.

RÉSULTATS : On n'a décelé aucune différence significative de taux d'intubation cæcale entre les deux groupes $(95,7 \%$ et $98,7 \%$ dans le groupe d'hystérectomie et le groupe témoin, respectivement; $\mathrm{P}=0,176)$. Le RRR brut de succès était de 0,29 (95\% IC 0,05 à 1,90). On n'a décelé aucune différence significative entre les groupes pour ce qui est de la sédation ou du type de colonoscope. On n'a observé aucune corrélation entre l'évaluation de la douleur par le gastroentérologue et par la patiente.

CONCLUSION : L'hystérectomie n'a pas réduit de manière significative le taux d'intubation cæcale, et on n'a constaté aucune différence décelable de perception de la douleur ou de dose de sédation. La colonoscopie demeure un excellent outil de dépistage et de diagnostic pour toutes les femmes.

Key Words: Cecal intubation; Colonoscopy; Hysterectomy; Pain; Sedation; Women

\footnotetext{
$\mathrm{C}$ lolon cancer is one of the leading causes of death in Canada and the United States for both men and women (1). In 2009 , approximately 22,000 new cases of colorectal cancer were expected in Canada, with 9100 people dying from this disease (2). The United States Preventive Services Task Force updated recommendations include colonoscopy as a screening option for individuals at risk for colorectal cancer (3).
}

Total and complete colonoscopy is the gold standard procedure for the prevention and screening of colon cancer. Medical and financial resources may not permit screening colonoscopy for all average-risk patients older than 50 years of age, as recommended by clinical guidelines (2-4).

Retrospective data have been collected $(5,6)$, but few prospective studies have been performed. Anderson et al (5), and

${ }^{1}$ Hôpital Montfort, University of Ottawa, Ottawa, Ontario; ${ }^{2}$ University of Calgary, Calgary, Alberta

Correspondence: Dr Philip Hassard, Hôpital Montfort, 713 Montreal Road, Ottawa, Ontario K1K 0T2. Telephone 613-746-5393,

fax 613-746-4840, e-mail hassardp@rogers.com

Received for publication August 26, 2009. Accepted November 16, 2009 
Waye and Bashkoff (7) failed to demonstrate that hysterectomy affected the success rate of colonoscopy. However, Shah et al (6) determined that previous pelvic surgery increased the risk of incomplete colonoscopy.

Previous studies investigating factors that predict incomplete colonoscopy and difficulty in performing the procedure were limited by methodology, or examined different outcomes such as the use of different models of colonoscopes, the difference in the difficulty of performing the procedure between men and women and pain during sedation-free colonoscopy. There were also studies investigating the determinants of successful sigmoidoscopy only $(5,8-10)$. Ramakrishnan and Scheid $(9,10)$ found that women who had a previous hysterectomy and later underwent a colonoscopy had more incomplete and less successful procedures. In 2003, Adams et al (8) determined that women who had previously undergone a hysterectomy experienced more pain during colonoscopy.

Many studies have investigated the completion rate of colonoscopy after hysterectomy, without, however, reporting the amount of sedation needed and the associated complications. In the present prospective study, pain perception, as well as the sedation requirements of participants during colonoscopies, was evaluated and compared between women who had previously undergone hysterectomy and those who had not.

The purpose of the current study was to evaluate the completion rate - defined as successful cecal intubation - during colonoscopy in women, 45 to 80 years of age, who underwent a previous hysterectomy and those without any previous abdominal surgeries. By definition, successful cecal intubation is achieved when the tip of the colonoscope permits complete, full evaluation of the cecum.

\section{METHODS}

The present study was approved by the Council of Research Ethics Board at SCO Health Service in Ottawa, Ontario.

During a six-month period, all female patients presenting for an outpatient colonoscopy at the Montfort Hospital (Ottawa, Ontario) were asked to participate in the study. A total of 508 female patients, 45 to 80 years of age, consented to participate. Inclusion criteria consisted of female patients 45 to 80 years of age. Exclusion criteria included the following: male patients, inadequate bowel preparation, impaired ability to give informed consent, colon cancer, inflammatory bowel disease, and history of previous abdominal or pelvic surgery other than tubal ligation and hysterectomy. In total, 229 women were deemed eligible to participate in the study. Based on their history, the participants were then divided into control and hysterectomy groups.

Bowel preparation consisted of a polyethylene glycol solution (4 L), phosphosoda or sodium picosulfate (Picosalax, Ferring BV, The Netherlands) taken the day before examination. A group of five specialty-certified gastroenterologists performed the procedures at the Montfort Hospital endoscopy unit. The Olympus Q180AL, Q160AL, Q160L or pediatric colonoscope with a CLV-10 light source (Olympus, Japan) were used for visualization via a colour video monitor (Trinitron PVM-20M2MD or PVM-20L2MD, Sony, Japan).

All consenting patients were asked to complete a preintervention questionnaire to determine whether they qualified for the study, as well as a postintervention questionnaire to evaluate pain control. Questionnaires were also distributed to the endoscopist for every patient who received and completed a questionnaire. The collected data included patient age, medical and surgical history - specifying hysterectomy, irritable bowel syndrome, inflammatory bowel disease and colon cancer. The endoscopist questionnaire included clinician's identification, model of colonoscope used, procedural time, sedation requirements, whether the cecum was intubated, perception of the patient's pain rated by the endoscopist, difficulty performing the procedure, use of a visual analogue scale, and complications, presence or absence of colon cancer, as well as whether preparation was adequate. On the final questionnaire, the patient was asked to rate the intensity of pain experienced during the procedure on a visual analogue scale.

Data analysis was performed using SPSS version 15.0 (SPSS Inc, USA). The minimal clinically important difference was $10 \%$ to $15 \%$, determined by a literature review. The expected SD in cecal intubation is $85 \%$. Overall, the cecal intubation rate was anticipated to be $95 \%$, while in the hysterectomy group, the expected rate was $85 \%$. A power of $95 \%$ was chosen, with 170 participants needed to satisfy the above parameters. The data are summarized as mean $( \pm \mathrm{SD})$, median and interquartile range, or counts with percentages. Differences in success rates between study groups were assessed with a logistic regression model adjusted for patient age. Other continuous intervention characteristics were compared using the Student's $t$ test or the Mann-Whitney U test. Correlation between patients' and gastroenterologists' perception of pain resulting from the procedure was assessed using the Pearson correlation coefficient. A two-sided $\mathrm{P} \leq 0.05$ was considered to be statistically significant.

\section{RESULTS}

A total of 508 participants underwent colonoscopies during a six-month period from July 2007 to January 2008. Of these, 229 met the study's inclusion criteria. The average age was 59 years (range 45 to 80 years). Intubation of the cecum was achieved in 215 participants. There were missing data pertaining to cecal intubation in nine patients. The overall adjusted completion rate was $97.8 \%$, and the success rate for the hysterectomy group was $95.7 \%$ versus $98.7 \%$ for the control group. The success rate showed no significant differences in cecal intubation rate between the two groups (OR 0.29, 95\% CI 0.05 to $1.90 ; \mathrm{P}=0.176$ ). Similar results were obtained when the model was adjusted for patient age (OR $0.41,95 \%$ CI 0.06 to $2.58 ; \mathrm{P}=0.178$ ).

There was a weak correlation between patients' and gastroenterologists' perception of pain resulting from the procedure $(\mathrm{r}=0.462)$ with discordance in both directions. Postprocedure pain perception also failed to show a significant difference between the two groups $(\mathrm{P}=0.513)$ (Figure 1). No significant differences were found in the sedation requirements for fentanyl ( $\mathrm{P}=0.6)$ and midazolam ( $\mathrm{P}=0.923)$ for either group.

No significant difference in procedural difficulty was detected between the two groups $(\mathrm{P}=0.13)$. Furthermore, no significant difference was found between the two groups regarding the type of colonoscope used for the procedure $(\mathrm{P}=0.673)$. Two patients were diagnosed with colon cancer. Two complications occurred: oversedation in one patient (hysterectomy group) and a superficial nonperforating mucosal tear at $20 \mathrm{~cm}$ in one patient in the control group. No adverse outcomes were associated with these complications. 


\section{DISCUSSION}

The main finding of the present study was that the completion rate of colonoscopy was similar in women regardless of whether they underwent previous pelvic surgery, including hysterectomy. Earlier studies show that colonoscopy is more difficult to perform in women than in men because of anatomical differences. Takahashi et al (11) stated that the female pelvis is deeper and more rounded than its male counterpart. This may predispose to loop formation in the sigmoid colon. Colonoscopy can be challenging in some women who have had a hysterectomy because of adhesions to the sigmoid colon (12). Saunders et al (13) concluded that female colonic length was greater than in men and may be responsible for more technically difficult colonoscopy in women. We did not investigate colon length; however, no difference in technical difficulty was identified between the groups. Hysterectomy and previous pelvic surgery are controversial as causes of incomplete colonoscopy in women (14). The crude completion rate of colonoscopy is lower in women posthysterectomy according to a study by Church (15); however, our study failed to demonstrate such a difference.

The analyses performed by Church (15), Hull and Church (16) as well as Lee et al (17) demonstrated a trend toward increased difficulty and significantly more pain for women who had a hysterectomy or previously underwent abdominal surgery. However, in our study, no significant increase in the difficulty of the procedure was detected between the groups. Assessment of pain can be difficult to perform and replicate because it is a subjective parameter. Halfens et al (18) reported that the correlation of nurses' assessment with patients' assessment of pain shows reasonable agreement (66\% accurate), with nurses tending to overestimate pain. In the present study, pain perception graded by the gastroenterologist did not correlate with the patient's perception of pain experienced during the procedure. Because no difference in sedation requirements was found between the two groups, caution must be taken by gastroenterologists when interpreting patient pain because this may affect the amount of sedation administered to the patient. This could lead to under- or oversedation, and result in possible harm to the patient. The choice of colonoscope, including the use of a pediatric colonoscope, had no overall affect on the procedure or success rate.

Only two minor complications occurred in the present study. The minimal rate of these events may have been influenced by the fact the study was performed in a high-volume centre staffed only with experienced gastroenterologists.

Given the elevated success rate in both study groups, our study may be underpowered to demonstrate a statistically significant difference in the primary outcome. Therefore, a larger population would be required in future studies. However, even if a difference was detectable, it is unlikely that the magnitude of this difference would affect clinical recommendations. There are other limitations in the current study. Gastroenterologists not being blinded to the patients' clinical history may have influenced the success rate of the procedures as well as the colonoscopy technique of the endoscopist. As in the study by Adams et al (8), patient history of hysterectomy was self-reported and patients were not divided into vaginal versus abdominal hysterectomy subgroups - a differentiation not made in the current study. When assessing pain perception,

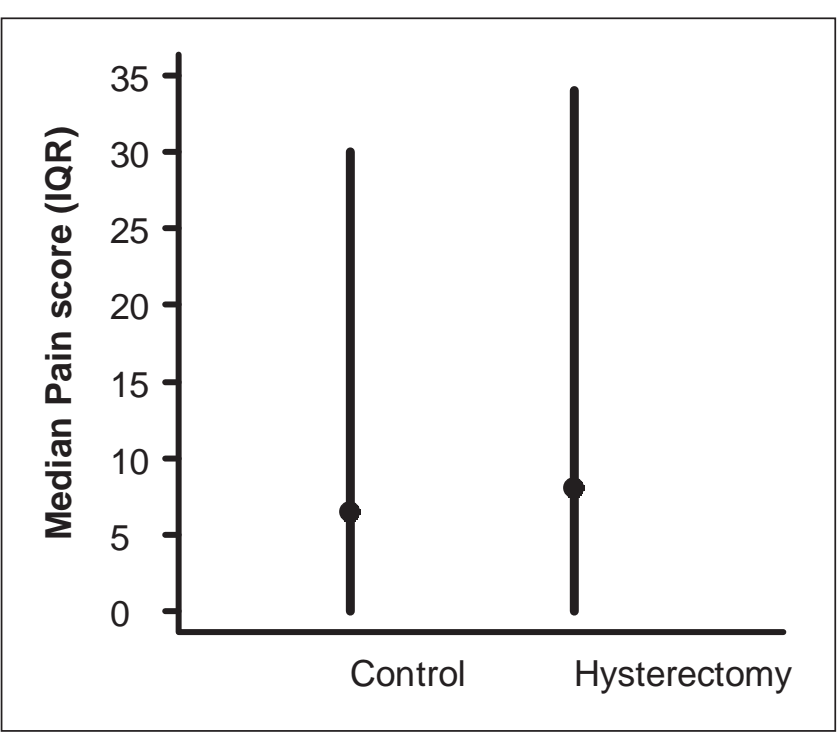

Figure 1) Postprocedure patient pain perception using a visual analogue scale $(P=0.513)$. IQR Interquartile range

patient anxiety before the procedure was not taken into account. Anxiety could influence the extent of pain perceived by the patient. The amnestic property of midazolam could also impair the patient's ability to recall pain.

\section{CONCLUSION}

We were unable to detect a significant difference between the control and hysterectomy groups for cecal intubation, pain perception, procedural difficulty and sedation requirements. In both groups, a high completion rate of cecal intubation was achieved. Only minimal complications were encountered. Colonoscopy remains an excellent screening and diagnostic tool for all women.

ACKNOWLEDGEMENTS: The authors thank the Montfort Hospital (Ottawa, Ontario) endoscopy unit nursing and support staff for the remarkable work performed, without which this research would not have been possible. The authors also thank P Finès for assistance with data entry and analysis.

DISCLOSURE: The authors have no financial interests or conflicts of interest to declare.

\section{REFERENCES}

1. Jemal A, Siegel R, Ward E, et al. Cancer statistics. CA Cancer J Clin 2006;56:106-30.

2. Statistics Canada: Canadian Cancer Registry: <www.statcan.gc.ca $>$ (Accessed on April 17, 2009).

3. Whitlock EP, Lin JS, Liles E, Beil TL, Fu R. Screening for colorectal cancer: A targeted, updated systematic review for the U.S. Preventive Services Task Force. Ann Intern Med 2008;149:638-58.

4. Winawer S, Fletcher R, Rex D, et al. Colorectal cancer screening and surveillance: Clinical guidelines and rationale-update based on new evidence. Gastroenterology 2003;124:544-60.

5. Anderson JC, Messina CR, CohnW, et al. Factors predictive of difficult colonoscopy. Gastrointest Endosc 2001;54:558.

6. Shah HA, Paszat LF, Saskin R, Stukel TA, Rabeneck L. Factors associated with incomplete colonoscopy:

A population-based study. Gastroenterology 2007;132:2297-303.

7. Waye JD, Bashkoff E. Total colonoscopy: Is it always possible? Gastrointest Endosc 1991;37:152. 
8. Adams C, Cardwell C, Cook C, Edwards R, Atkin WS, Morton DG. Effect of hysterectomy status on polyp detection rates at screening flexible sigmoidoscopy. Gastrointest Endosc 2003;57:848-53.

9. Ramakrishnan K, Scheid DC. Predictors of incomplete flexible sigmoidoscopy. J Am Board Fam Pract 2003;16:478-84.

10. Ramakrishnan K, Scheid DC. Selecting patients for flexible sigmoidoscopy. Determinants of incomplete depth of insertion. Cancer 2005;103:1179-85.

11. Takahashi Y, Tanaka H, Kinjo M, Sakumoto K. Prospective evaluation of factors predicting difficulty and pain during sedation-free colonoscopy. Dis Colon Rectum 2005;48:1295-300.

12. Cirocco WC, Rusin LC. Factors that predict incomplete colonoscopy. Dis Colon Rectum 1995;38:964-8.
13. Saunders BP, Fukumoto M, Halligan S, et al. Why is colonoscopy more difficult in women? Gastrointest Endosc 1996;43(2 Pt 1):124-6.

14. Wolf JL. Uniquely women's issues in colorectal cancer screening. Am J Gastroenterol 2006;101(Suppl 12):S625-9.

15. Church JM. Complete colonoscopy: How often? And if not, why not? Am J Gastroenterol 1994;89:556-60.

16. Hull T, Church JM. Colonoscopy - how difficult, how painful? Surg Endosc 1994;8:784-7.

17. Lee SK, Kim TI, Shin, SJ, Kim BC, Kim WH. Impact of prior abdominal or pelvic surgery on colonoscopy outcomes. J Clin Gastroenterol 2006;40:711.

18. Halfens R, Evers G, Abu-Saad H. Determinants of pain assessment by nurses. Int J Nurs Stud 1990;27:43. 


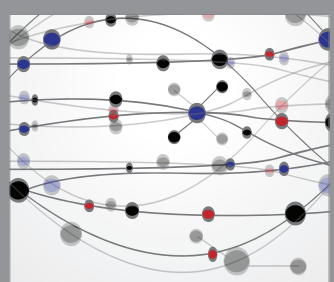

The Scientific World Journal
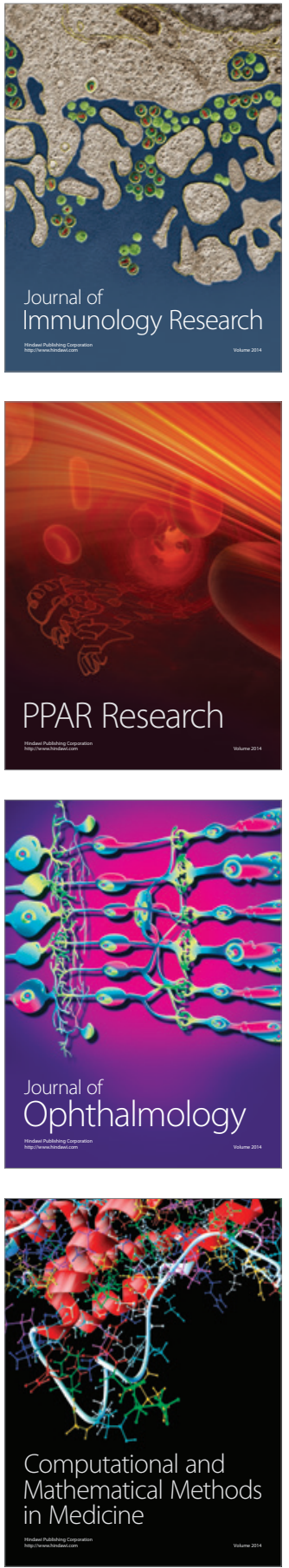

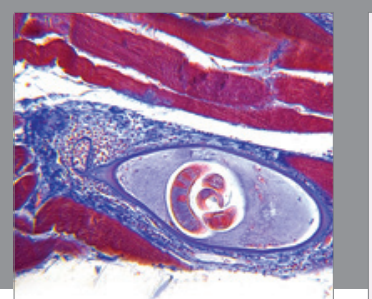

Gastroenterology Research and Practice

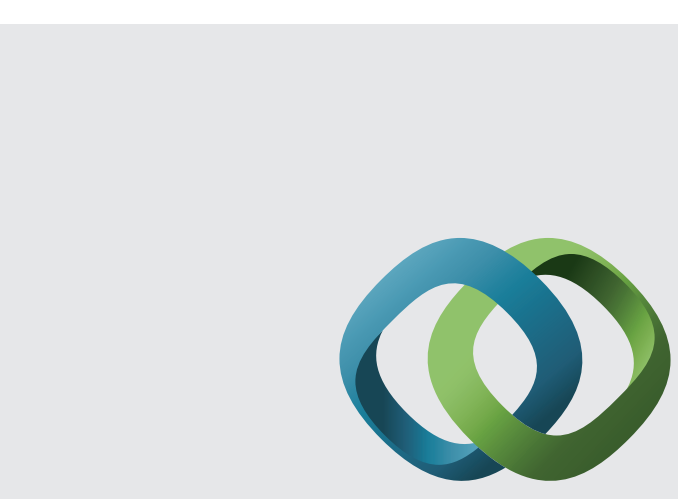

\section{Hindawi}

Submit your manuscripts at

http://www.hindawi.com
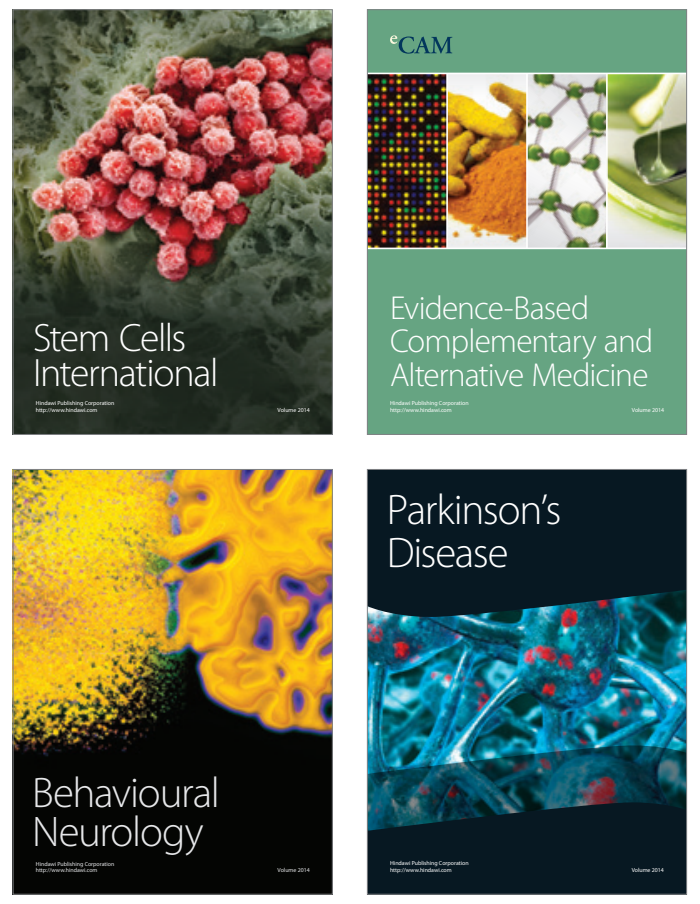
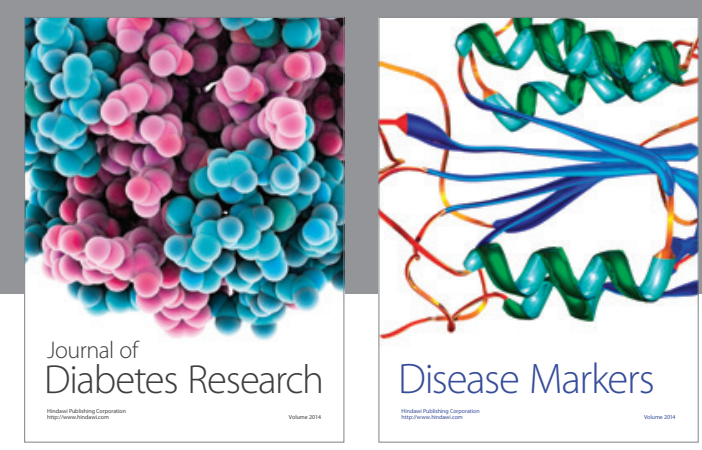

Disease Markers
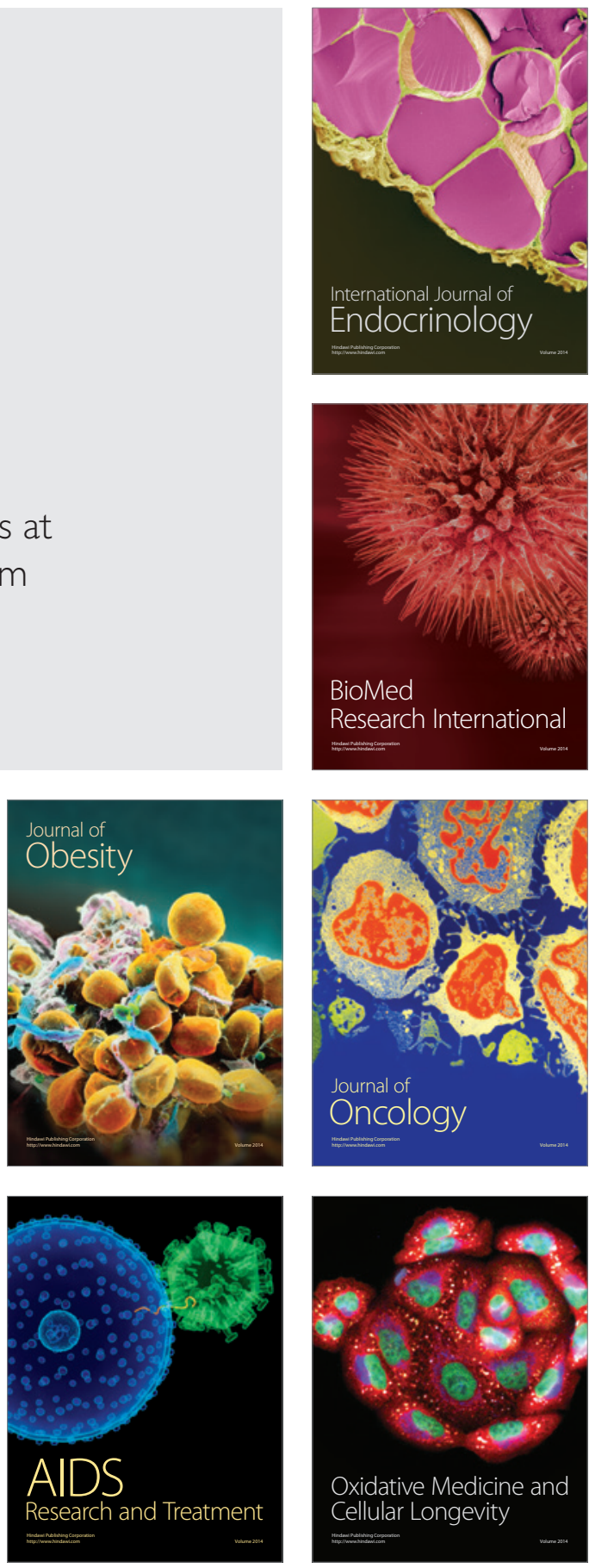